\title{
Article
}

\section{Mimicking Pathogenic Invasion with the Complexes of Au(SG)-Engineered Assemblies and Folic Acid}

Chunlei Zhang, Amin Zhang, Wenxiu Hou, Tianliang Li, Kan Wang, Qian Zhang, Jesús M. De La Fuente, Weilin Jin, and Daxiang Cui

ACS Nano, Just Accepted Manuscript • DOI: 10.1021/acsnano.8b00196 • Publication Date (Web): 03 May 2018

Downloaded from http://pubs.acs.org on May 3, 2018

\section{Just Accepted}

"Just Accepted" manuscripts have been peer-reviewed and accepted for publication. They are posted online prior to technical editing, formatting for publication and author proofing. The American Chemical Society provides "Just Accepted" as a service to the research community to expedite the dissemination of scientific material as soon as possible after acceptance. "Just Accepted" manuscripts appear in full in PDF format accompanied by an HTML abstract. "Just Accepted" manuscripts have been fully peer reviewed, but should not be considered the official version of record. They are citable by the Digital Object Identifier (DOI®). "Just Accepted" is an optional service offered to authors. Therefore, the "Just Accepted" Web site may not include all articles that will be published in the journal. After a manuscript is technically edited and formatted, it will be removed from the "Just Accepted" Web site and published as an ASAP article. Note that technical editing may introduce minor changes to the manuscript text and/or graphics which could affect content, and all legal disclaimers and ethical guidelines that apply to the journal pertain. ACS cannot be held responsible for errors or consequences arising from the use of information contained in these "Just Accepted" manuscripts. 


\section{Mimicking Pathogenic Invasion with the Complexes of $\mathrm{Au}_{22}(\mathrm{SG})_{18}$-Engineered Assemblies and Folic Acid}

Chunlei Zhang, ${ }^{*},+*$ Amin Zhang, ${ }^{\dagger}$ Wenxiu Hou, ${ }^{\dagger}$ Tianliang $\mathrm{Li}^{\dagger}{ }^{\dagger}$ Kan Wang, ${ }^{\dagger}$ Qian Zhang, ${ }^{\dagger}$ Jesús M de la Fuente, ${ }^{\dagger}{ }^{\S}$ Weilin Jin, ${ }^{\dagger}$ and Daxiang Cui ${ }^{*}{ }^{\dagger}, *$

${ }^{\dagger}$ Institute of Nano Biomedicine and Engineering, Shanghai Engineering Research Center for Intelligent Instrument for Diagnosis and Therapy, Department of Instrument Science \& Engineering, School of Electronic Information and Electrical Engineering, Shanghai Jiao Tong University, 800 Dongchuan Road, Shanghai 200240, China

${ }^{ \pm}$National Center for Translational Medicine, Collaborative Innovational Center for System Biology, Shanghai Jiao Tong University, 800 Dongchuan Road, Shanghai 200240, China

${ }^{\S}$ Instituto de Ciencia de Materiales de Aragón (ICMA-CSIC), Universidad de Zaragoza \& CIBER-BBN, 50009 Zaragoza, Spain

Corresponding Author: E-mail: dxcui@sjtu.edu.cn and chunleizhang@sjtu.edu.cn 


\begin{abstract}
Biological systems provide the richest spectrum of sophisticated design for materials engineering. We herein provide a paradigm of $\mathrm{Au}_{22}(\mathrm{SG})_{18}(\mathrm{SG}$, glutathione thiolate)-engineered and hydrogen bonds engaged assemblies for mimicking capsid protein self-assembly. The water-evaporation-induced self-assembly method allows discrete ultrasmall gold nanoclusters (GNCs) to be self-assembled into super-GNCs assemblies (SGNCs) ranging from nano-, meso- to microscale in water-dimethylsulfoxide binary solvents in a template-free manner. After removing free and hydration layer water molecules, the formation of SGNCs is engaged by the collective cohesion of hydrogen bonds between glutathione ligands of gradually approaching GNCs. Then, a series of tightly orchestrated cellular events induced by the complexes of $\mathrm{Au}_{22}(\mathrm{SG})_{18}$-engineered assemblies and folic acid are demonstrated to mimic the invasion of eukaryotic cells by pathogens. Firstly, the activation of macropinocytosis mimics the macropinocytic entry used by the pathogens to invade host cells. Then the cytoplasmic vacuolization is a mimicry of vacuolating effects induced by the oligomeric vacuolating toxins secreted by some bacteria. Lastly, the escaping from macropinosomes into cytosol is in a vacuolating toxin's strategy. The findings demonstrate the capabilities of artificial pathogens to emulate the structures and functions of natural pathogens.
\end{abstract}

Keywords: biomimetic materials, cytoplasmic vacuolization, gold nanoclusters, hydrogen bonds, macropinocytosis, self-assembly 
As both biological processes understanding and material engineering capabilities have dramatically increased, the tools from the biology community are enabling the bioinspired materials design to mimic biological functionality. ${ }^{1,2}$ However, how to precisely control the interactions between cells and bioinspired materials within a concerted design methodology remains a grand challenge. ${ }^{3}$ Specifically, bacterial and viral pathogens have evolved a wealth of distinctive molecular solutions to infiltrate into host cells in terms of the structure and functions, representing the biomimetic engineering strategies to the design of bioinspired materials. ${ }^{4,5}$ The bottom-up self-assembly strategy, referring to the process of constructing stable and hierarchically-ordered aggregates from building units, has been explored at large among the biological structures of pathogens. ${ }^{6,7}$ Some bacterial proteinaceous toxins self-assemble multimeric pores on the plasma membrane to invade host cells. ${ }^{8}$ Besides, capsids, the protective protein shell of viruses designed to enclose the viral genome, are self-assembling structures of capsomeres, relying on the combination of weak attractive or repulsive forces that, in concert, provide the capsids with noteworthy thermodynamic and mechanical properties. ${ }^{6,9}$ Therefore, chemical mimicry of capsid self-assembly can be exploited to construct nanostructures with biological functionality. ${ }^{1,10}$ Structurally well-defined gold nanoclusters (GNCs), which connects the yawning gap between atoms and colloidal nanoparticles with dimensions reaching the Fermi wavelength of an electron $(\mathrm{ca} .0 .7 \mathrm{~nm}),{ }^{11}$ are ideal building blocks to be scaled up into superstructures via self-assembly. ${ }^{12}$

Cytoplasmic vacuolization has been widely observed in mammalian cells after exposure to bacterial or viral pathogens as well as to a variety of amine-containing weakly basic lipophilic substances. ${ }^{4,13-15}$ Specifically, the actions of inducing irreversible cellular vacuolization by Helicobacter pylori vacuolating toxin, Mycoplasma pneumoniae CARDS toxin, and Vibrio cholerae haemolysin represent important examples to investigate the pleiotropic effects of bacterial toxins on mammalian cells. ${ }^{4,13,14}$ Though different molecular mechanisms of vacuole formation have been proposed, ${ }^{4,14}$ the physicochemical properties of inducers underlie the action 
of transient and irreversible vacuolization. Similarly, insights into the physicochemical interactions between nanomaterials and biological systems are of paramount importance in the process of laboratory to the clinical practice. ${ }^{16}$ The interactions essentially exemplified by interacting with biological molecules (i.e., small biological molecules and biological macromolecules) and cells. To achieve the necessary control over the formation of protein coronas, particle membrane wrapping and engulfment, internalization pathways, and fate of internalized cargo, fully understanding of 'nano-bio' interface and establishing fundamental principles of the nanomaterial-cell interactions has become critical important and urgent. ${ }^{16}$ More data on the vacuole formation obtained in this work prompt us to revisit working models for the vacuolization mechanism.

In addition to the self-assembled structures, pathogens opportunistically exploit some strategies for binding to cell surface and entering the cytosol from endosomes. ${ }^{17}$ Macropinocytosis, distinguished by non-selectively bulk uptake of solute macromolecules and fluid, is exploited by some pathogens to promote their entry into host cells through receptor-dependent means. ${ }^{5}$ Moreover, by using macropinocytosis, the pathogens can escape the endosomal pathways involved in antigen presentation. Thus, the macropinocytic pathway can be utilized as an avenue to deliver anti-cancer drugs specifically into cytosol. ${ }^{18}$ After entering the host cells, the limitation arises from the translocation of the bacterial toxins and viral genes into the cytosol. Nevertheless, by the means of pore formation on the endosomal membrane, the proton sponge effect, as well as the fusion with the endosomal membrane, bacterial and viral pathogens provide the richest strategies to the problem of endosomal escape. ${ }^{17}$ To achieve the necessary control over the internalization pathways and the fate of endocytosed cargo, developing bio-inspired nanostructures mimicking biological functionality are substantially challenging but indispensable in nano-biochemistry.

Herein, we developed a synthetic control strategy for constructing $\operatorname{Au}_{22}(\mathrm{SG})_{18}(\mathrm{SG}$, glutathione thiolate)-engineered super-assemblies to mimic capsid protein self-assembly. The glutathione (GSH), a naturally occurring and readily available 
tripeptide, has been widely chosen as the thiolate ligand for the synthesis of GNCs with broad application prospects in cancer imaging and therapy and some other fields of nanomedicine. ${ }^{19-21}$ However, since the first synthesis of $\mathrm{Au}_{22}(\mathrm{SG})_{18}$ clusters with red emission around $665 \mathrm{~nm}$ and a quantum yield of $\sim 8 \%$ in 2003 by Xie and co-workers, very few reports on the applications of $\mathrm{Au}_{22}(\mathrm{SG})_{18}$ clusters are available while amount of work are still focused on $\mathrm{Au}_{25}$ clusters. ${ }^{22,23}$ By controlling the dynamic intermolecular forces among $\mathrm{Au}_{22}(\mathrm{SG})_{18}$ clusters, spherical super-assemblies with size ranging from nano-, meso- to microscale can be constructed in water-dimethylsulfoxide (DMSO) binary solvents in a template-free manner. Moreover, the complexes of $\mathrm{Au}_{22}(\mathrm{SG})_{18}$-engineered super-GNCs assemblies and folic acid (abbreviated as SGNCs-FA), morphologically being similar to a sphere virion, can mimic the virus entry into host cells by macropinocytosis in a receptor-dependent manner. Subsequently, the vacuolating effects and the entry to the cytosol from macropinosomes are similar to what occurs with oligomeric vacuolating toxins. The artificial pathogens constructed from the bottom-up self-assembly strategy can mimic the biological structures of pathogens as well as their biological functions.

\section{Results and Discussion}

Virion-like assemblies formation. Firstly, atomically precise $\mathrm{Au}_{22}(\mathrm{SG})_{18}$ clusters were prepared, identified, and characterized (Figures S1-S3). The $\mathrm{Au}_{22}(\mathrm{SG})_{18}$ clusters in water luminesce with a maximum at $\sim 665 \mathrm{~nm}$, and exhibit two characteristic bands at 450 and $515 \mathrm{~nm}$ in the UV-vis spectrum (Figure 1a). TEM image of the $\mathrm{Au}_{22}(\mathrm{SG})_{18}$ shows the mean core size distribution around $1.3 \mathrm{~nm}$ (Figure 1b). For the sake of clarity, the ellipsoidal $\mathrm{Au}_{22}(\mathrm{SG})_{18}$ clusters, consisted of a theoretically predicted bitetrahedron $\mathrm{Au}_{7}$ core, an $\mathrm{Au}_{6}$ ring, and three $\mathrm{Au}_{3}$ staple motifs, ${ }^{22,}{ }^{24}$ can be considered as the subunit of capsid-capsomeres with a molecular weight of $9.8 \mathrm{kDa}$ (Figure S3). Inspired by the peptides/proteins-engineered self-assembly, strategies of effectively engaging hydrogen bonds (H-bonds) networks among the GSH-capped GNCs by obstructing the fierce H-bonds competition to water molecules should be 
feasible to engineer $\mathrm{Au}_{22}(\mathrm{SG})_{18}$-based biomimetic assemblies. ${ }^{25,26}$ In this regard, after adding widely used cosolvent DMSO to GNCs aqueous solution to disrupt the H-bonds networks in water, we apply a vacuum-rotary evaporation procedure to control the self-assembly process of GNCs. Under the heating temperature of $50{ }^{\circ} \mathrm{C}$ and $0.095 \mathrm{MPa}$ vacuum pressure for $40 \mathrm{~min}, 20 \mathrm{~mL}$ of GNCs solution $(0.1$ and 0.2 $\mathrm{mg} / \mathrm{mL}, 18 \mathrm{~mL} \mathrm{H}_{2} \mathrm{O}+2 \mathrm{~mL}$ DMSO, $\mathrm{pH} \sim 7$ ) was concentrated into $\sim 4 \mathrm{~mL}$, respectively. Then the samples were collected and examined by transmission electron microscope (TEM) and dynamic light scattering (DLS). Highly compact spherical super-GNCs assemblies (SGNCs) with diameters of $169.2 \pm 39.6$ and $490.2 \pm 113.9$ $\mathrm{nm}$ were formed, respectively (Figure $1 \mathrm{c}, \mathrm{d}$ ). When adjusting the $\mathrm{pH}$ values of the initial GNCs aqueous solution to 3.5 and 10, the electrokinetic $\zeta$-potential of GNCs was $\sim-0.5$ and $-26.8 \mathrm{mV}$, respectively. Subsequently, the SGNCs with diameters of $1480.0 \pm 299.0$ and $62.9 \pm 14.5 \mathrm{~nm}$ were formed, respectively (Figure 1e, f). When the lower of the $\mathrm{pH}$ value led the greater proportion of protonated carboxyl groups in GSH ligands, elevated H-bonds and depressed electrostatic repulsive force among GSH ligands contributed to the formation of much larger SGNCs (Figure S4). Changing the $\mathrm{pH}$ back to 10.0 was followed by a disassembled process into individual building blocks- $\mathrm{Au}_{22}(\mathrm{SG})_{18}$ clusters, a similar reversible behavior in formation of protein assemblies (Figure S5). ${ }^{27}$ When compared with core size, the enlarged hydrodynamic diameters of SGNCs could be contributed to the extended hydration layer (Figure S6).

Although the molecular arrangement of the hydration layer remains elusive, the existence of hydration water surrounding protein surfaces has been universally acknowledged. ${ }^{28}$ Similarly, the high stability of GNCs in high salt aqueous solution implies the existence of a short-range hydration force, arising from H-bonds and ion hydration of water-interactive groups of GSH ligands (Figure S7). Therefore, the water molecules in the above self-assembly system can be subdivided into three categories: hydration layer water, free water, and DMSO H-bonded water. In this water-evaporation-induced self-assembly process, the preferential evaporation of free 
water was followed by the hydration water molecules deprived from the GNCs surfaces, making the GNCs come in close proximity. Then the H-bonds networks were engaged among GSH ligands, starting the self-assembly process (Figure 1g). Thus, the integrated structural system of SGNCs in final binary solvents can be rationalized by arranging hydration layer to surround SGNCs and the outermost 1DMSO: $2 \mathrm{H}_{2} \mathrm{O}$ layer to stabilize hydration layer (Figure S8). ${ }^{29}$

Considering the substantial influence of the water-DMSO binary solvents on the formation of SGNCs, we envision that regulating the composition range of binary solvents through dialysis could constitute an alternative. Specifically, the SGNCs with diameters of $1092.8 \pm 224.8$ and $228.6 \pm 40.1 \mathrm{~nm}$ were formed when GNCs aqueous solution was dialyzed against DMSO and $N, N$-dimethylformamide (DMF), respectively (Figure 2). Previous investigations have confirmed that the dielectric constant values of water-DMSO cosolvents are larger than those of water-DMF cosolvents at the same fractions over the entire composition range. ${ }^{30}$ Thus, a larger dielectric constant value could more efficiently screen the repulsive electrostatic forces between negatively charged GNCs, so the SGNCs formed in water-DMSO cosolvents are much larger than those formed in water-DMF cosolvents. The dialysis induced self-assembly accords substantially with water-evaporation-induced self-assembly on the engagement of H-bonds among GSH ligands by displacement of hydration water molecules.

To impart the $\mathrm{Au}_{22}(\mathrm{SG})_{18}$-engineered SGNCs with a biological identity, modulation of surface characteristics of SGNCs (core size around $62.9 \mathrm{~nm}$ ) with folic acid (FA) was carried out. As an amphiphilic molecule, the hydrophobic pteroate moiety of FA forms H-bonds and hydrophobic interactions with folate receptors (FR), whereas the extremely hydrophilic glutamate moiety engages $\mathrm{H}$-bonds with $\mathrm{FR}^{31}$ In the as-prepared non-covalent bonds combined SGNCs-FA complexes, the extremely hydrophilic glutamate moiety of FA forms H-bonds with SGNCs, whereas the hydrophobic pteroate moiety tends to stick out. The SGNCs-FA complexes exhibited the characteristic absorption peak of FA at 280 and $350 \mathrm{~nm},{ }^{32}$ as well as the 
characteristic absorption peak of GNCs at $515 \mathrm{~nm}$ (Figure S9).

Cytoplasmic vacuolization induced by SGNCs-FA complexes. Folate receptor $\alpha$ (FR $\alpha$ ), typically over-expressed in cancerous cells, mediates the entry of FA into cells through endocytosis. ${ }^{33}$ Human gastric (MGC-803), breast (MCF-7) and lung (A549) cancer cell lines with different FR $\alpha$ expression levels were studied for interactions with the SGNCs-FA complexes (Figure 3a). When exposed to the SGNCs-FA complexes, nascent vacuoles initially originated from peri-nuclear region and increased in size over time (Figure S10). However, neither FA nor SGNCs or the basic mixtures of GNCs + FA induce cytoplasmic vacuoles (data not shown). Then, the neutral red uptake (NRU) assay, mainly based on the amounts of the neutral red (acidotropic dye) accumulated within cells, ${ }^{34}$ was performed to depict the extent of vacuolization. As shown in Figure 3b, the staining of vacuoles indicated their acidic environment. More specifically, the uptake amounts of SGNCs-FA complexes indicated by flow cytometry and the extent of vacuolization at indicated time points were coincident with the expression levels of FR $\alpha$ (Figure $3 c, d$ ). These results identified the decisive role of FR $\alpha$-mediated endocytosis in determining vacuolating effects.

To explore the ultrastructure of cytoplasmic vacuoles and the intracellular trafficking pathways of SGNCs-FA complexes, the time- and space-detailed analysis was performed by Bio-TEM. As shown in Figure 4a-c, the vacuoles were mostly round and electron-clear at TEM. Additionally, ultrastructure observation demonstrated that a substantial number of SGNCs-FA complexes were internalized in the endocytic vesicles in proximity of the plasma membrane after $30 \mathrm{~min}$ of co-incubation (Figure 4d). Subsequently, endocytic vesicles moved deeper into the cytosol towards nucleus at $1 \mathrm{~h}$ (Figure 4e). Meanwhile, the SGNCs-FA complexes appeared to be fleeing from the intra-lumen into the cytosol by permeabilizing the membrane of endocytic vesicles, at which point the transformation from endocytic vesicles into inclusion-free vacuoles took place. And then vacuole-vacuole fusion became widespread, giving rise to larger vacuoles at $2 \mathrm{~h}$ (Figure $4 \mathrm{f}$ ). In contrast, gold 
nanoparticles and nanorods were mainly endocytosed in endosomes and eventually accumulated in endolysosomes incapable of reaching cytosol. ${ }^{35,36}$

Activation of macropinocytosis by the SGNCs-FA complexes. Given the huge size and irregular shape of the endocytic vesicles, macropinocytosis may already be occurring. ${ }^{37}$ To elucidate whether macropinocytosis, characterized by internalizing large quantities of solute and fluid phase,$^{38,39}$ is the primary endocytosis mechanisms of SGNCs-FA complexes, lucifer yellow (LY) uptake assay was performed. ${ }^{40}$ As shown in Figure 5a and Figure S11, the extracellular fluid-phase tracers LY, once co-ingested into the cells, was clearly discernible within vacuoles with no signs of leakage into the cytosol. Furthermore, pharmacological inhibition studies demonstrated that the uptake of SGNCs-FA complexes and cytoplasmic vacuoles formation was greatly suppressed when the cells were pretreated with cytochalasin D (Cyto D) for perturbing actin filament polymerization and amiloride for interfering actin remodeling (Figure S6). ${ }^{40}$ On the basis of the above data, we elucidated that the vacuoles were derived from macropinosomes and the membranes integrity was preserved in this transformation process. Considering the intraluminal acidic $\mathrm{pH}$, the ontogeny of the vacuoles might be closely connected with acidic endosomal-lysosomal organelles. Therefore, the distribution of organelle markers in vacuolated cells was examined. Immunofluorescent staining results indicated that membranes of vacuoles were enriched in Rab7 (Figure 5b and Figure S12), a late endosome marker in regulating early-to-late endosomal maturation. ${ }^{41}$ In contrast, the early endosomes marker EEA1 was not co-localized well with vacuolar membranes (Figure S13). ${ }^{42}$ These results demonstrated that the macropinosomes recruit protein from late endosomes during maturation process.

\section{The connection between macropinosomal escape and cytoplasmic} vacuolization. Furthermore, immunostaining of vacuolated cells confirmed the enrichment of the vacuolar-type $\mathrm{H}^{+}$-ATPase (V-ATPase) around the vacuolar membranes (Figure 5b and Figure S14). Accordingly, pharmacological inhibition study demonstrated that the selective V-ATPase inhibitor bafilomycin A1 (Baf-A1) 
can effectively suppressed the cytoplasmic vacuolization (Figure S15). ${ }^{43} \mathrm{We}$ concluded that V-ATPase was responsible for the intraluminal acidic environment and a $\mathrm{pH}$ gradient was necessary for the formation of vacuoles. Interestingly, the formation of vacuoles was also efficiently blocked by chloride anions $\left(\mathrm{Cl}^{-}\right)$channel inhibitor (Figure S15). The most likely explanation was that endocytosed SGNCs-FA complexes would promote the influx of $\mathrm{Cl}^{-}$, thereby stimulating the $\mathrm{H}^{+}$pumping activity of the V-ATPase to maintain the acidic conditions of vacuoles. ${ }^{44}$ In this case, the entry of $\mathrm{Cl}^{-}$and $\mathrm{H}^{+}$represents the driving force for transport of $\mathrm{Na}^{+}$or $\mathrm{K}^{+}$and leads to a net uptake of $\mathrm{NaCl}$ or $\mathrm{KCl}$, resulting in a high intraorganellar osmotic pressure and driving water move into the vacuoles. ${ }^{44}$ Furthermore, to identify the role of water influx in the cytoplasmic vacuolization, the co-localization of aquaporins (AQP), specific regulators of water homeostasis in crossing biological membranes, ${ }^{45}$ with vacuoles was examined. Immunostaining of vacuolated cells showed that aquaporin-1 (AQP1) was present on the membranes of vacuoles (Figure 5b). Additionally, vacuoles formation was almost completely suppressed by a potent AQP1 inhibitor $\mathrm{HAuCl}_{4}$, whereas the uptake efficacy of SGNCs-FA complexes was not affected (Figure 6). ${ }^{46}$ We reasoned from these data that the V-ATPase, $\mathrm{Cl}^{-}$channel, and AQP-1 were co-responsible for water diffusion into the vacuoles.

To further investigate the connection between macropinosomal escape and water influx-induced cytoplasmic vacuolization, we again used ultrastructure observation after pharmacological inhibition studies. Ultrastructures of V-ATPase, $\mathrm{Cl}^{-}$channel, and AQP-1 inhibitors pretreated MGC-803 cells indicated no apparent signs of water influx into the macropinosomes. Meanwhile, the SGNCs-FA complexes were still entrapped within the macropinosomes (Figure S16). These data favor the possibility that the influx of water into the macropinosomes facilitates the macropinosomal escape. However, irreversible vacuolization resulted cell death through hyper-activated macropinocytosis is mainly observed in a variety of secreted protein toxins of bacteria and enveloped virus. ${ }^{47}$ But the notable elevated reactive oxygen species (ROS) level after exposure to the SGNCs-FA complexes had no appreciable 
cytotoxicity (Figure S17). Collectively, we depicted the process of how the SGNCs-FA complexes mimicking pathogenic invasion (Figure 7). The promoted cytosolic cargo delivery by the transient vacuolization of the SGNCs-FA complexes indicates the development of applicable therapeutic approaches.

\section{Conclusions}

In summary, by using the water-DMSO binary solvents to control the dynamic intermolecular interactions among GSH-capped GNCs, we have constructed $\mathrm{Au}_{22}(\mathrm{SG})_{18}$-engineered spherical super-assemblies with size spanning three orders of magnitude in a template-free manner. The self-assembly process relies on the engagement of multiple H-bonds among GSH ligands via displacing hydration water molecules surrounding $\mathrm{Au}_{22}(\mathrm{SG})_{18}$ clusters, which will provide insights into the natural protein self-assembling mechanism when the molecular basis for how proteins detect specific stimuli and assemble into protein self-assemblies are still poorly understood. More specifically, by transferring biological molecules FA on the surface of SGNCs to obtain a biological identity, the complexes of SGNCs-FA activate FR $\alpha$-mediated macropinocytosis in cancer cells, analogous to the endocytosis mechanism exploited by some viruses to invade host cells. Subsequently, as the macropinosomes rapidly mature into phase-lucent cytoplasmic vacuoles, the endocytosed SGNCs-FA complexes are escaping from macropinosomes into the cytosol, which can be paralleled with the cytoplasmic vacuolization induced by the oligomeric vacuolating toxins. The biomimetic approaches revealed in our work could aid future 'architecture-by-design' nanomedicine with configurable geometries and functions. Although we accomplished this work by using SGNCs with core size around $62.9 \mathrm{~nm}$, some other nano to micron-sized SGNCs can be harnessed to extend biomimetic design including protein-, exosome-, leukocyte-, erythrocyte-, and platelet-like nanomaterials to explore basic biological mechanisms and cellular therapies.

\section{Materials and Methods}


Materials. Gold (III) chloride trihydrate $\left(\mathrm{HAuCl}_{4} \cdot 3 \mathrm{H}_{2} \mathrm{O}, 99 \%\right)$, folic acid (FA) were obtained from Sinopharm Chemical Reagent Co., Ltd. (Shanghai, China). Neutral red, Baf-A1, Cyto D, amiloride hydrochloride hydrate ( $\geq 98 \%)$, DMSO, and DMF were purchased from Aladdin Reagent Co. Ltd. (Shanghai, China). Borane tert-butylamine complex (97\%) was obtained from Energy Chemical Reagent Co. Ltd. (Shanghai, China). Lucifer Yellow $\mathrm{CH}$ dipotassium salt, 4',6-diamidino-2-phenylindole (DAPI), 5-Nitro-2-(3-phenylpropylamino)benzoic acid (NPPB), and 2',7'-dichlorofluorescein diacetate (DCFH-DA) were purchased from Sigma-Aldrich(St. Louis, MO, USA). Rabbit monoclonal anti-EEA1 antibody (2411) and anti-Rab7 antibody (2094) were purchased from Cell Signaling Technology (Danvers, MA, USA). Rabbit polyclonal anti-AQP1 antibody (ab15080) was purchased from Abcam (Cambridge, UK). Rabbit polyclonal anti-folate receptor alpha antibody and anti-V-ATPase antibody were purchased from Abgent (San Diego, California, USA). Human gastric (MGC-803), breast (MCF-7) and lung (A549) cancer cell lines were available in the Cell Bank of Type Culture Collection of Chinese Academy of Sciences. All solutions were prepared using highly purified water $(18.2 \mathrm{M} \Omega \mathrm{m})$ taken from an ELGA LabWater system (PURELAB ${ }^{\text {TM }}$ ELGA LabWater, UK).

Preparation, purification, and separation of $\mathbf{A u}_{22}(\mathbf{S G})_{18}$ clusters. The red-emitting GNCs were synthesized from a modified method reported by our group. ${ }^{32}$ The details of synthesis procedures, purification by fractional precipitation, and native PAGE separation of the $\mathrm{Au}_{\mathrm{n}}(\mathrm{SG})_{\mathrm{m}}$ compounds were demonstrated in supporting information.

Self-assembly of gold nanoclusters. A. Vacuum-rotary water-evaporation-induced self-assembly. Self-assembly reaction was conducted in $50 \mathrm{~mL}$ round-bottom flasks on a vacuum-rotary evaporator. Firstly, $18 \mathrm{~mL}$ GNCs aqueous solution (containing 2 $\mathrm{mg}$ or $4 \mathrm{mg} \mathrm{Au} 22(\mathrm{SG})_{18} \mathrm{NCs}$ ) and $2 \mathrm{~mL} \mathrm{DMSO}$ were mixed together and sonicated for $5 \mathrm{~min}$, followed by adjusting the $\mathrm{pH}$ to 7 by $1 \mathrm{M} \mathrm{HCl}$. Thus, the concentration of GNCs in water-DMSO binary solvents was 0.1 and $0.2 \mathrm{mg} / \mathrm{mL}$, respectively. Afterward, the sample flasks are swirled at $100 \mathrm{rpm}$ on a water bath at $50{ }^{\circ} \mathrm{C}$ under $0.095 \mathrm{MPa}$ vacuum pressures. An external recirculating chiller was used to cool the trap and was controlled to $-5^{\circ} \mathrm{C}$. At indicated time points ( $\left.\sim 40 \mathrm{~min}\right)$, when the total volume was reduced to about $4 \mathrm{~mL}$, the evaporation procedure was stopped and let the samples restore to room temperature (RT) before next treatment. The $\mathrm{pH}$ values of water-DMSO binary solvents had great influence on the size of super-assemblies. For 
samples (GNCs, $0.1 \mathrm{mg} / \mathrm{mL}$ ) with the $\mathrm{pH}$ values of initial water-DMSO solution were adjusted to 3.5 and 10 with $1 \mathrm{~N} \mathrm{HCl}$ or $1 \mathrm{~N} \mathrm{NaOH}$, the use of a rotary evaporator in this process was identical as mentioned earlier. B. Dialysis-induced self-assembly. Firstly, the $2 \mathrm{~mL}$ of the $\mathrm{Au}_{22}(\mathrm{SG})_{18} \mathrm{NCs}$ aqueous solution $(1 \mathrm{mg} / \mathrm{mL}, \mathrm{pH} 7)$ was placed in a regenerated cellulose dialysis bag (MWCO: $1.0 \mathrm{kDa}$ ) and dialyzed against $200 \mathrm{~mL}$ of DMSO or DMF at $25^{\circ} \mathrm{C}$ for $1 \mathrm{~h}$, respectively. Within about $1 \mathrm{~h}$, the solution in the dialysis bag became turbid with some precipitate precipitated out. Then the solution and precipitate in the dialysis bag was collected and resuspended in water. The formation of SGNCs in the dialysis process against DMSO or DMF was confirmed by electron microscopy characterization and DLS.

Formation of SGNCs-FA complexes. The final volume of as-assembled SGNCs (with core size around $62.9 \mathrm{~nm}$ ) solution was about $4 \mathrm{~mL}$ (containing $2 \mathrm{~mL}$ DMSO). Then $0.5 \mathrm{mg}$ FA (50 mg/mL, dissolved in DMSO) was added to the SGNCs solution followed by stirring overnight at RT. The mixture solution was transferred into a dialysis bag (MWCO 3500) and dialyzed against ultrapure water for two days. The final product was precipitated out by addition a certain amount of $\mathrm{NaCl}$ (to $20 \mathrm{mM}$ ) and methanol (to $60 \%, \mathrm{v} / \mathrm{v}$ ). The SGNCs-FA complexes were dissolved in water at a concentration of $4 \mathrm{mg} / \mathrm{mL}$.

Observation of cell ultrastructure. For the TEM sample preparation, three types of cells were seeded on $35 \mathrm{~mm}$ culture dish. The cells were grown to $80 \%$ confluence and exposed to $0.3 \mathrm{mg} / \mathrm{mL}$ SGNCs-FA dissolved in serum-free DMEM medium for $30 \mathrm{~min}, 1.5 \mathrm{~h}, 2 \mathrm{~h}$, and $3 \mathrm{~h}$. At the indicated time points, cells were washed three times with $0.01 \mathrm{M}$ PBS and harvested using trypsin-EDTA, centrifuged, and fixed in $2.5 \%$ (wt/vol) glutaraldehyde in $0.01 \mathrm{M}$ PBS (pH 7.4) overnight at $4{ }^{\circ} \mathrm{C}$. Cells were next rinsed in $0.01 \mathrm{M}$ PBS and centrifuged. Pellets were post-fixed in $1 \%(\mathrm{wt} / \mathrm{vol})$ osmium tetroxide in 0.01M PBS ( $\mathrm{pH} 7.4$ ) for $2 \mathrm{~h}$. Dehydration was achieved by sequential treatments with $25,50,75,95$ and $100 \%$ ethanol followed by acetone. The samples were then transferred to propylene oxide, and embedded in epoxy resin. Ultrathin sections were prepared by a Leica EM UC 6 ultramicrotome and stained with uranyl acetate followed by lead citrate. Then the ultrathin sections were mounted on copper grids and examined with FEI Tecnai G2 Spirit BioTwin electron microscope at 120 $\mathrm{kV}$ using Gatan 832 CCD camera.

Lucifer yellow staining of cytoplasmic vacuoles. Localization of extracellular fluid-phase marker lucifer yellow (LY) was monitored by incubating cells in the 
presence of $0.15 \mathrm{mg} / \mathrm{mL}$ SGNCs-FA and $0.5 \mathrm{mg} / \mathrm{mL}$ lucifer yellow in serum-free DMEM medium for $3 \mathrm{~h}$ at $37^{\circ} \mathrm{C}$. Cells were washed twice with $0.01 \mathrm{M}$ PBS, fixed in $4 \%$ paraformaldehyde, and visualized with inverted microscope (IX 71, Olympus) equipped with a $100 \times$ objective and Rolera-MGI Plus back-illuminated EMCCD camera and an Olympus U-MWIBA3 filter set (BP460-495, DM505, BA510-550).

Immunofluorescent staining of vacuolated cells. Cells were plated in 4-chamber glass-bottom $35 \mathrm{~mm}$ dish at $60 \%$ confluence per chamber $24 \mathrm{~h}$ before treatment. Then, cells were incubated with $0.3 \mathrm{mg} / \mathrm{mL}$ SGNCs-FA in serum-free DMEM medium for 3 $\mathrm{h}$ at $37^{\circ} \mathrm{C}$. After washing twice with $0.01 \mathrm{M} \mathrm{PBS}$, cells were fixed in $4 \%$ paraformaldehyde for $10 \mathrm{~min}$ at $37^{\circ} \mathrm{C}$, and then permeabilized in PBS containing $0.2 \%$ Triton-X-100 for 5 min and blocked with PBS containing 10\% goat serum for 1 $\mathrm{h}$ at RT. Next, cells were incubated with primary antibodies diluted to 1:150 (EEA1, Rab7, V-ATPase, and AQP1) in PBS with $1 \%$ goat serum overnight at $4{ }^{\circ} \mathrm{C}$. Cells were washed twice with PBS containing $1 \%$ goat serum, incubated with secondary antibodies diluted to 1:250 (Alexa Fluor 488 goat anti-rabbit) in PBS with 1\% goat serum for $1 \mathrm{~h}$ at RT. The nuclei of the cells were stained with DAPI $(1 \mu \mathrm{g} / \mathrm{mL}$ in PBS) for $5 \mathrm{~min}$ at RT. Finally, the cells were observed with Confocal Quantitative Image Cytometer CQ1 (Yokogawa Electric Corporation, Tokyo, Japan). The blue channel (excitation $405 \mathrm{~nm}$, emission 447/60 nm) was used for the acquisition of DAPI, green channel (excitation $488 \mathrm{~nm}$, emission 525/50 nm) was used for the acquisition of immunofluorescence. Images were processed using CQ1 software and ImageJ 1.50 (NIH, Bethesda, ML).

Flow cytometry analysis. All flow cytometry analyses were performed on a BD FACSCalibur (BD Biosciences, Mountain View, CA) and the data were processed with FlowJo 7.6 software. To analyze the uptake of SGNCs-FA complexes in cells, the cells were plated in 6-well plates and then allowed to adhere overnight. The cells were incubated with $0.3 \mathrm{mg} / \mathrm{mL}$ SGNCs-FA complexes in serum-free DMEM medium, then collected and immediately analyzed by flow cytometry at $3 \mathrm{~h}$. FL-3 ( $\lambda_{\mathrm{em}}$, $650-700 \mathrm{~nm}$ ) channel was selected to collect the fluorescence signal of cells using an $488 \mathrm{~nm}$ argon laser as an excitation source.

Pharmacological inhibition studies. To evaluate the pharmacological inhibition effects of vacuolization, the cells were by pretreated with macropinocytosis inhibitors (amiloride $100 \mu \mathrm{g} / \mathrm{mL}$ + Cyto D $2 \mathrm{mM}, 2 \mathrm{~h}$ ), AQP1 inhibitor ( $\mathrm{HAuCl}_{4} 200 \mu \mathrm{M}, 6 \mathrm{~min}$ ), V-ATPase inhibitor Baf-A1 (100 nM, $30 \mathrm{~min})$, and chloride ion $\left(\mathrm{Cl}^{-}\right)$channel blocker 
NPPB $(100 \mu \mathrm{M}, 1 \mathrm{~h})$, respectively. Subsequently, the cells were co-incubated with 0.3 $\mathrm{mg} / \mathrm{mL}$ SGNCs-FA complexes for $3 \mathrm{~h}$ and then analysed by NRU assay and flow cytometry. Cells without inhibitors pretreating were taken as control groups.

Statistical Analysis. The statistical analysis was performed in quintuplicate unless otherwise indicated. The data were expressed as mean values \pm standard deviation (SD). Statistical difference was calculated with paired sample using Student's $t$-test comparison at a significance level of $p<0.05$.

\section{ASSOCIATED CONTENT}

\section{Supporting Information}

The Supporting Information is available free of charge on the ACS Publications website.

Additional figures of materials characterization for GNCs and SGNCs; figures of cytoplasmic vacuolation assay, lucifer yellow staining and immunofluorescent staining of vacuolated cells.

\section{AUTHOR INFORMATION}

\section{Corresponding Author}

*E-mail: dxcui@sjtu.edu.cn and chunleizhang@sjitu.edu.cn

Notes

The authors declare no competing financial interest.

\section{ACKNOWLEDGMENTS}

This work is supported by National Key Basic Research Program of China (Grant Nos. 2010CB933901, and 2015CB931802), The National Key Research and Development Program of China (Grant No. 2017FYA0205301), China Postdoctoral Science Foundation (Grant No. 2016M601602), the National Natural Science Foundation of China (Grant No.81571835). We thank Dr. Lei Feng from Instrumental Analysis Center of Shanghai Jiao Tong University and Dr. Hui Wang from Waters Technologies (Shanghai) Ltd. for help with ESI-MS experiment.

\section{REFERENCES}


1. Green, J. J.; Elisseeff, J. H., Mimicking Biological Functionality with Polymers for Biomedical Applications. Nature 2016, 540, 386-394.

2. Zhang, S., Fabrication of Novel Biomaterials through Molecular Self-Assembly. Nat. Biotechnol. 2003, 21, 1171-1178.

3. Nel, A. E.; Madler, L.; Velegol, D.; Xia, T.; Hoek, E. M.; Somasundaran, P.; Klaessig, F.; Castranova, V.; Thompson, M., Understanding Biophysicochemical Interactions at the Nano-Bio Interface. Nat. Mater. 2009, 8, 543-557.

4. Cover, T. L.; Blanke, S. R., Helicobacter Pylori VacA, a Paradigm for Toxin Multifunctionality. Nat. Rev. Microbiol. 2005, 3, 320-332.

5. Mercer, J.; Helenius, A., Virus Entry by Macropinocytosis. Nat. Cell Biol. 2009, 11, 510-520.

6. Wan, W.; Kolesnikova, L.; Clarke, M.; Koehler, A.; Noda, T.; Becker, S.; Briggs, J. A., Structure and Assembly of the Ebola Virus Nucleocapsid. Nature 2017, 551, 394-397.

7. Whitesides, G. M.; Grzybowski, B., Self-Assembly at All Scales. Science 2002, 295, 2418-2421.

8. Montecucco, C.; Papini, E.; Schiavo, G., Bacterial Protein Toxins Penetrate Cells Via a Four-Step Mechanism. FEBS Lett. 1994, 346, 92-98.

9. Miller, R. A.; Presley, A. D.; Francis, M. B., Self-Assembling Light-Harvesting Systems from Synthetically Modified Tobacco Mosaic Virus Coat Proteins. J. Am. Chem. Soc. 2007, 129, 3104-3109.

10. Parodi, A.; Molinaro, R.; Sushnitha, M.; Evangelopoulos, M.; Martinez, J. O.; Arrighetti, N.; Corbo, C.; Tasciotti, E., Bio-Inspired Engineering of Cell- and Virus-Like Nanoparticles for Drug Delivery. Biomaterials 2017, 147, 155-168.

11. Zheng, J.; Nicovich, P. R.; Dickson, R. M., Highly Fluorescent Noble Metal Quantum Dots. Annu. Rev. Phys. Chem. 2007, 58, 409-431.

12. Hou, W.; Xia, F.; Alfranca, G.; Yan, H.; Zhi, X.; Liu, Y.; Peng, C.; Zhang, C.; de la Fuente, J. M.; Cui, D., Nanoparticles for Multi-Modality Cancer Diagnosis: Simple Protocol for Self-Assembly of Gold Nanoclusters Mediated by Gadolinium Ions. Biomaterials 2017, 120, 103-114.

13. Figueroa-Arredondo, P.; Heuser, J. E.; Akopyants, N. S.; Morisaki, J. H.; Giono-Cerezo, S.; Enríquez-Rincón, F.; Berg, D. E., Cell Vacuolation Caused by Vibrio cholerae Hemolysin. Infect. Immun. 2001, 69, 1613-1624.

14. Johnson, C.; Kannan, T.; Baseman, J. B., Cellular Vacuoles Induced by Mycoplasma pneumoniae CARDS Toxin Originate from Rab9-Associated Compartments. PLoS One 2011, 6, e22877.

15. Ohkuma, S.; Poole, B., Cytoplasmic Vacuolation of Mouse Peritoneal Macrophages and the Uptake into Lysosomes of Weakly Basic Substances. J. Cell Biol. 1981, 90, 656-664.

16. Tsang, M. P.; Kikuchi-Uehara, E.; Sonnemann, G. W.; Aymonier, C.; Hirao, M., Evaluating Nanotechnology Opportunities and Risks through Integration of Life-Cycle and Risk Assessment. Nat. Nano. 2017, 12, 734-739.

17. Varkouhi, A. K.; Scholte, M.; Storm, G.; Haisma, H. J., Endosomal Escape Pathways for Delivery of Biologicals. J. Controlled Release 2011, 151, 220-228. 
18. Ha, K. D.; Bidlingmaier, S. M.; Liu, B., Macropinocytosis Exploitation by Cancers and Cancer Therapeutics. Front. Physiol. 2016, 7, 381.

19. Goswami, N.; Zheng, K.; Xie, J., Bio-NCs-the Marriage of Ultrasmall Metal Nanoclusters with Biomolecules. Nanoscale 2014, 6, 13328-13347.

20. Luo, Z.; Zheng, K.; Xie, J., Engineering Ultrasmall Water-Soluble Gold and Silver Nanoclusters for Biomedical Applications. Chem. Commun. 2014, 50, 5143-5155.

21. Zheng, K.; Setyawati, M. I.; Leong, D. T.; Xie, J., Antimicrobial Gold Nanoclusters. ACS nano 2017, 11, 6904-6910.

22. Yu, Y.; Luo, Z.; Chevrier, D. M.; Leong, D. T.; Zhang, P.; Jiang, D.-e.; Xie, J., Identification of a Highly Luminescent $\mathrm{Au}_{22}(\mathrm{SG})_{18}$ Nanocluster. J. Am. Chem. Soc. 2014, 136, 1246-1249.

23. Pyo, K.; Thanthirige, V. D.; Kwak, K.; Pandurangan, P.; Ramakrishna, G.; Lee, D., Ultrabright Luminescence from Gold Nanoclusters: Rigidifying the Au(I)-Thiolate Shell. $J$. Am. Chem. Soc. 2015, 137, 8244-8250.

24. Pei, Y.; Tang, J.; Tang, X.; Huang, Y.; Zeng, X. C., New Structure Model of $A_{u_{22}}(\mathrm{SR})_{18}$ : Bitetrahederon Golden Kernel Enclosed by $\left[\mathrm{Au}_{6}(\mathrm{SR})_{6}\right] \mathrm{Au}(\mathrm{I})$ Complex. J. Phys. Chem. Lett. 2015, 6, 1390-1395.

25. McManus, J. J.; Charbonneau, P.; Zaccarelli, E.; Asherie, N., The Physics of Protein Self-Assembly. Curr. Opin. Colloid Interface Sci. 2016, 22, 73-79.

26. Conti Nibali, V.; Havenith, M., New Insights into the Role of Water in Biological Function: Studying Solvated Biomolecules Using Terahertz Absorption Spectroscopy in Conjunction with Molecular Dynamics Simulations. J. Am. Chem. Soc. 2014, 136, 12800-12807.

27. An, S.; Kumar, R.; Sheets, E. D.; Benkovic, S. J., Reversible Compartmentalization of de Novo Purine Biosynthetic Complexes in Living Cells. Science 2008, 320, 103-106.

28. Otting, G.; Liepinsh, E.; Wuthrich, K., Protein Hydration in Aqueous Solution. Science 1991, 254, 974-980.

29. Wong, D. B.; Sokolowsky, K. P.; El-Barghouthi, M. I.; Fenn, E. E.; Giammanco, C. H.; Sturlaugson, A. L.; Fayer, M. D., Water Dynamics in Water/DMSO Binary Mixtures. J. Phys. Chem. B 2012, 116, 5479-5490.

30. Sengwa, R.; Khatri, V.; Sankhla, S., Structure and Hydrogen Bonding in Binary Mixtures of $\mathrm{N}, \mathrm{N}$-Dimethylformamide with Some Dipolar Aprotic and Protic Solvents by Dielectric Characterization. Indian J. Chem. 2009, 48, 512-519.

31. Chen, C.; Ke, J.; Zhou, X. E.; Yi, W.; Brunzelle, J. S.; Li, J.; Yong, E.-L.; Xu, H. E.; Melcher, K., Structural Basis for Molecular Recognition of Folic Acid by Folate Receptors. Nature 2013, 500, 486-489.

32. Zhang, C.; Li, C.; Liu, Y.; Zhang, J.; Bao, C.; Liang, S.; Wang, Q.; Yang, Y.; Fu, H.; Wang, K.; Cui, D., Gold Nanoclusters-Based Nanoprobes for Simultaneous Fluorescence Imaging and Targeted Photodynamic Therapy with Superior Penetration and Retention Behavior in Tumors. Adv. Funct. Mater. 2015, 25, 1314-1325.

33. Srinivasarao, M.; Galliford, C. V.; Low, P. S., Principles in the Design of Ligand-Targeted Cancer Therapeutics and Imaging Agents. Nat. Rev. Drug Discov. 2015, 14, 203-219. 
34. Miyashita, S.-I.; Sagane, Y.; Suzuki, T.; Matsumoto, T.; Niwa, K.; Watanabe, T., "Non-Toxic" Proteins of the Botulinum Toxin Complex Exert In-vivo Toxicity. Sci. Rep. 2016, 6, 31043.

35. Chithrani, B. D.; Ghazani, A. A.; Chan, W. C., Determining the Size and Shape Dependence of Gold Nanoparticle Uptake into Mammalian Cells. Nano Lett. 2006, 6, 662-668.

36. Huang, P.; Bao, L.; Zhang, C.; Lin, J.; Luo, T.; Yang, D.; He, M.; Li, Z.; Gao, G.; Gao, B., Folic Acid-Conjugated Silica-Modified Gold Nanorods for X-Ray/CT Imaging-Guided Dual-Mode Radiation and Photo-Thermal Therapy. Biomaterials 2011, 32, 9796-9809.

37. Conner, S. D.; Schmid, S. L., Regulated Portals of Entry into the Cell. Nature 2003, 422 , 37-44.

38. Lim, J. P.; Gleeson, P. A., Macropinocytosis: An Endocytic Pathway for Internalising Large Gulps. Immunol. Cell Biol. 2011, 89, 836-843.

39. Kaplan, I. M.; Wadia, J. S.; Dowdy, S. F., Cationic TAT Peptide Transduction Domain Enters Cells by Macropinocytosis. J. Controlled Release 2005, 102, 247-253.

40. Liu, X.; Wu, F.; Tian, Y.; Wu, M.; Zhou, Q.; Jiang, S.; Niu, Z., Size Dependent Cellular Uptake of Rod-Like Bionanoparticles with different aspect ratios. Sci. Rep. 2016, 6, 24567.

41. Rink, J.; Ghigo, E.; Kalaidzidis, Y.; Zerial, M., Rab Conversion as a Mechanism of Progression from Early to Late Endosomes. Cell 2005, 122, 735-749.

42. Christoforidis, S.; McBride, H. M.; Burgoyne, R. D.; Zerial, M., The Rab5 Effector Eea1 Is a Core Component of Endosome Docking. Nature 1999, 397, 621-625.

43. Yoshimori, T.; Yamamoto, A.; Moriyama, Y.; Futai, M.; Tashiro, Y., Bafilomycin A1, a Specific Inhibitor of Vacuolar-Type $\mathrm{H}(+)$-ATPase, Inhibits Acidification and Protein Degradation in Lysosomes of Cultured Cells. J. Biol. Chem. 1991, 266, 17707-17712.

44. Russo, M. A.; Morgante, E.; Russo, A.; Van Rossum, G.; Tafani, M., Ouabain-Induced Cytoplasmic Vesicles and Their Role in Cell Volume Maintenance. BioMed Res. Int. 2015, 2015, 487256-487269

45. Verkman, A. S.; Anderson, M. O.; Papadopoulos, M. C., Aquaporins: Important but Elusive Drug Targets. Nat. Rev. Drug Discov. 2014, 13, 259-277.

46. Yang, B.; Kim, J. K.; Verkman, A., Comparative Efficacy of $\mathrm{HgCl}_{2}$ with Candidate Aquaporin-1 Inhibitors DMSO, Gold, TEA $^{+}$and Acetazolamide. FFEBS Lett. 2006, 580, 6679-6684.

47. Maltese, W. A.; Overmeyer, J. H., Methuosis: Nonapoptotic Cell Death Associated with Vacuolization of Macropinosome and Endosome Compartments. Am. J. Pathol. 2014, 184, 1630-1642. 
Figure 1. Water-evaporation-induced $\mathrm{Au}_{22}(\mathrm{SG})_{18}$ clusters self-assembly. (a) UV-vis absorption and photoluminescence (PL) spectra of $\mathrm{Au}_{22}(\mathrm{SG})_{18}$ clusters. (b)TEM image and core size distribution of $\mathrm{Au}_{22}(\mathrm{SG})_{18}$ clusters. (c-f) TEM images of four SGNCs samples formed in the water-DMSO binary solvents at $50{ }^{\circ} \mathrm{C}$ under $0.095 \mathrm{MPa}$ vacuum pressures for 40 min with different conditions: (c) $0.1 \mathrm{mg} / \mathrm{mL} \mathrm{GNCs,} \mathrm{pH} \sim 7$; (d) $0.2 \mathrm{mg} / \mathrm{mL}$ GNCs, $\mathrm{pH} \sim 7$; (e) $0.1 \mathrm{mg} / \mathrm{mL}$ GNCs, $\mathrm{pH} \sim 10$; (f) $0.1 \mathrm{mg} / \mathrm{mL}$ GNCs, $\mathrm{pH} \sim 3.5$. (g) Schematic representation of the dynamic water-evaporation-induced GNCs self-assembly process in the water-DMSO binary solvents.

Figure 2. Dialysis-induced and solvent-dependent SGNCs formation. TEM images of the formed SGNCs when GNCs aqueous solution dialyzed against (a) DMSO and (b) DMF, respectively. (c-d) The core size distributions (histogram and Gaussian fitting) from TEM measurements of (a) and (b), respectively. Scale bars, $1 \mu \mathrm{m}$ (a); $200 \mathrm{~nm}$ (b). (e) Schematic representation of the dialysis process of GNCs aqueous solution against DMSO solvent: (1) solvents diffusion, (2) H-bonds engaged, (3) SGNCs formed, (4) SGNCs aggregated. When the turbid solution in the dialysis bag was collected, precipitated, and resuspended in water, the SGNCs rehydrated and dispersed in water. 
Figure 3. (a) Western blot analysis of FR $\alpha$ expression in MGC-803, MCF-7, and A549 cells. (b) Neutral red accumulated in MGC-803, MCF-7, and A549 cells after exposure to $0.15 \mathrm{mg} / \mathrm{mL}$ SGNCs-FA complexes for $2 \mathrm{~h}$, respectively. Arrowheads point at vacuoles completely stained with the neutral red. (c) Flow cytometry analysis of the cellular uptake of SGNCs-FA complexes. Red and cyan histograms represent fluorescence signals of the untreated cells, the cells treated with $0.15 \mathrm{mg} / \mathrm{mL}$ SGNCs-FA complexes for $2 \mathrm{~h}$, respectively. (d) The dose-response and time-course of cytoplasmic vacuolization induced by SGNCs-FA complexes. Neutral red accumulated in cells was quantified by $\mathrm{OD}_{550} \mathrm{~nm}$. The extent of cellular vacuolization was expressed as percent of the maximal observed uptake within the same experiment at the indicated time. All values shown were the average of quintuplicates $\pm S D$.

Figure 4. Ultrastructure observation of cytoplasmic vacuoles in (a) MGC-803, (b) MCF-7, and (c) A549 cell after co-incubation with $0.3 \mathrm{mg} / \mathrm{mL}$ SGNCs-FA complexes for $3 \mathrm{~h}$, respectively. The formation process of cytoplasmic vacuoles in MGC-803 cells at (d) $30 \mathrm{~min}$, (e) $1 \mathrm{~h}$, and (f) $2 \mathrm{~h}$ after co-incubation with $0.3 \mathrm{mg} / \mathrm{mL}$ SGNCs-FA complexes. Red arrows in (a-c) point at the vacuoles; red triangles in (d) point at endocytic vesicle; red and blue arrows in (e) indicate the endocytic vesicles which are transforming into vacuoles and SGNCs-FA complexes which are escaping from vesicles into cytosol, respectively; red arrows in (f) indicate the fusion behaviors of cytoplasmic vacuoles. Abbreviation: N, nucleus. Scale bars, $1000 \mathrm{~nm}(\mathrm{a}-\mathrm{c}) ; 2 \mu \mathrm{m}(\mathrm{d})$; $1 \mu \mathrm{m}$ (inset of $\mathrm{d}, \mathrm{e}, \mathrm{f}$ ).

Figure 5. Fluorescent analysis of the cytoplasmic vacuoles. (a) Localization of LY in vacuolated MGC-803 cells induced by SGNCs-FA complexes. Arrowhead points at a subpopulation of LY-containing vacuoles. (b) Immunofluorescent staining of vacuolated MGC-803 cells for Rab7, AQP1, and V-ATPase. From right to left panel, representative DAPI blue fluorescence images of the nucleus, green fluorescence 
images of specific protein markers, brightfield microscopy images, and the merged images are presented. Arrowheads points at vacuoles. Scale bars, $20 \mu \mathrm{m}$. Abbreviations: LY, lucifer yellow; V-ATPase, vacuolar $\mathrm{H}^{+}$-ATPase; AQP1, Aquaporin 1; DAPI, 4'-6-diamidino-2-phenylindole.

Figure 6. Pharmacological inhibition of macropinocytosis and AQP1. (a) Flow-cytometry-based analysis of the cellular uptake of SGNCs-FA complexes after pretreated with inhibitors. The red, green, cyan, and orange histograms represented fluorescence signals of the untreated cells, the cells with macropinocytosis inhibitors (amiloride $100 \mu \mathrm{g} / \mathrm{mL}$ + Cyto D $2 \mathrm{mM}, 2$ h) pretreating and subsequent SGNCs-FA complexes exposure, the cells with $\mathrm{AQP1}$ inhibitor $\left(\mathrm{HAuCl}_{4} 200 \mu \mathrm{M}, 6 \mathrm{~min}\right)$ pretreating and subsequent SGNCs-FA complexes exposure, and the cells with SGNCs-FA complexes exposure. (b) The extent of SGNCs-FA-induced vacuolization in cells with or without inhibitors pretreating was determined by NRU assay. Cells without inhibitors pretreating but expose to SGNCs-FA complexes were taken as the control groups (set as 100\% vacuolization efficiency). The pharmacological inhibitors pretreating and SGNCs-FA complexes exposure conditions in (b) were the same as used in (a). All values shown were the average of quintuplicates \pm SD. Statistical differences were determined by Student's $t$-test, * significant against the control group, $P<0.001$.

Figure 7. Schematic representation of how the SGNCs-FA complexes mimicking pathogenic invasion by the activation of macropinocytosis, the use of macropinosomal escape and inducing cytoplasmic vacuolization. 

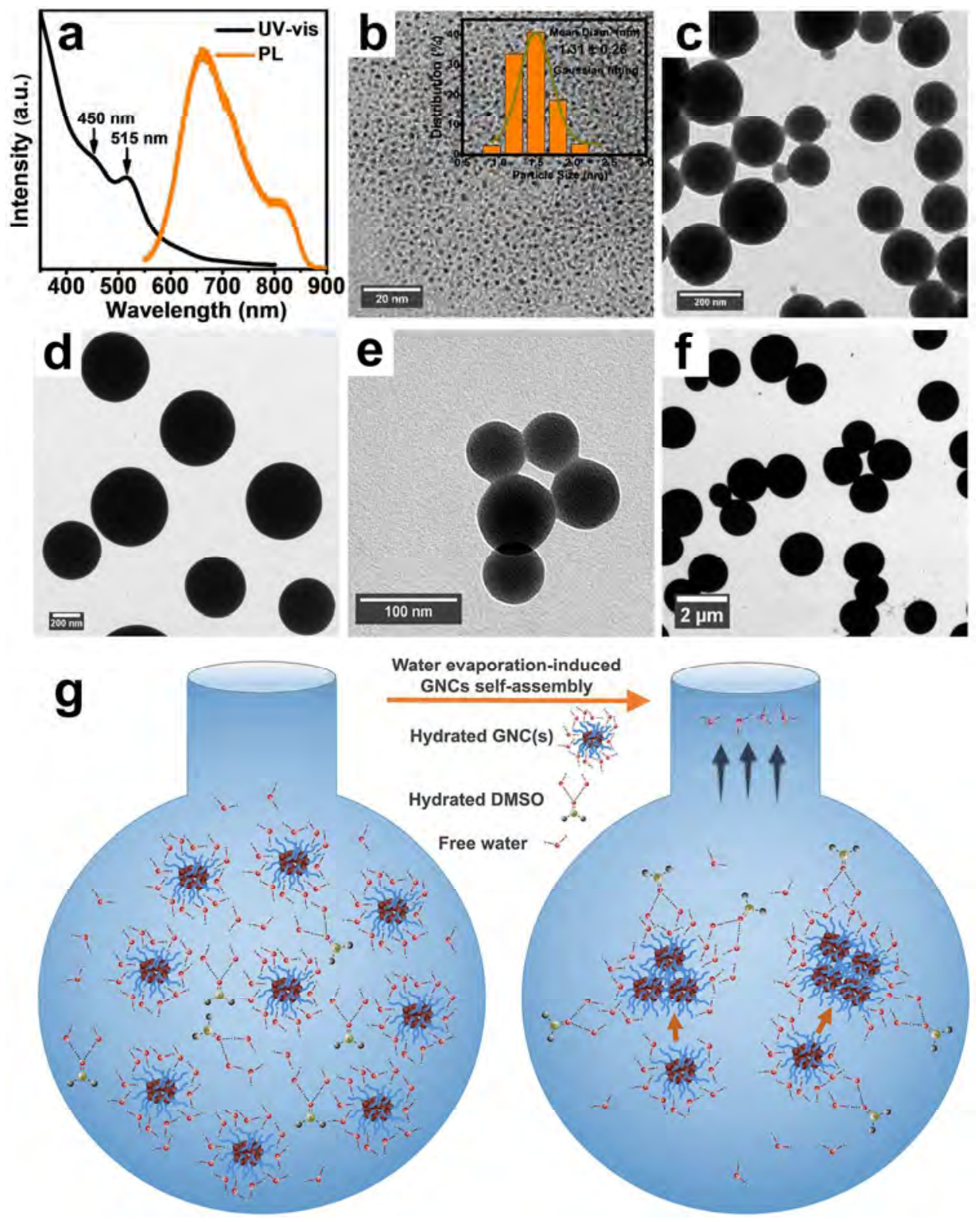

Figure 1. Water-evaporation-induced $\mathrm{Au}_{22}(\mathrm{SG})_{18}$ clusters self-assembly. (a) UV-vis absorption and photoluminescence (PL) spectra of $\mathrm{Au}_{22}(\mathrm{SG})_{18}$ clusters. (b)TEM image and core size distribution of $\mathrm{Au}_{22}(\mathrm{SG})_{18}$ clusters. (c-f) TEM images of four SGNCs samples formed in the water-DMSO binary solvents at $50{ }^{\circ} \mathrm{C}$ under $0.095 \mathrm{MPa}$ vacuum pressures for 40 min with different conditions: (c) $0.1 \mathrm{mg} / \mathrm{mL} \mathrm{GNCs,} \mathrm{pH} \sim 7$; (d) $0.2 \mathrm{mg} / \mathrm{mL}$ GNCs, pH 7; (e) $0.1 \mathrm{mg} / \mathrm{mL}$ GNCs, pH 10; (f) $0.1 \mathrm{mg} / \mathrm{mL}$ GNCs, pH $~ 3.5$. (g) Schematic representation of the dynamic water-evaporation-induced GNCs self-assembly process in the water-DMSO binary solvents. 

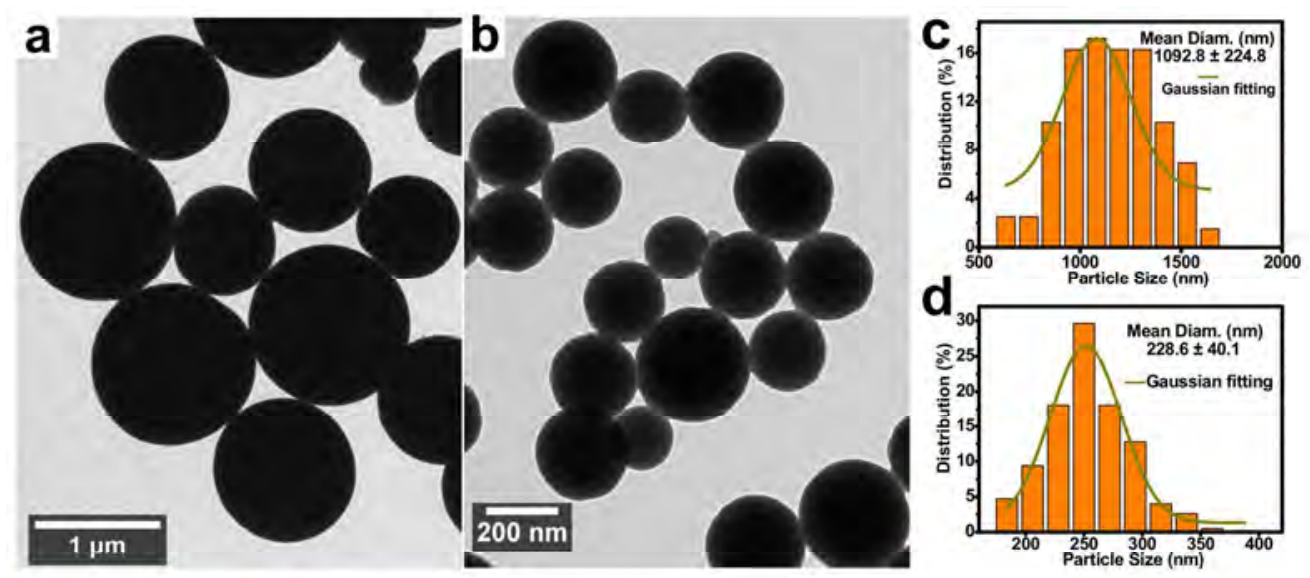

Outside $\begin{gathered}\text { Semipermeable } \\ \text { membrane }\end{gathered}$ Inside

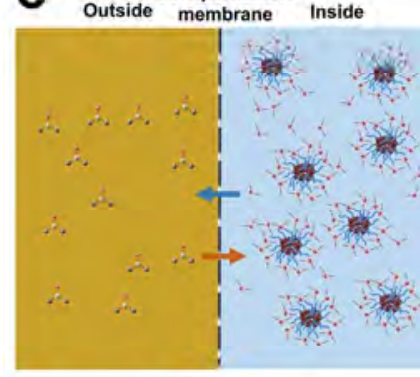

(1) Solvents diffusion

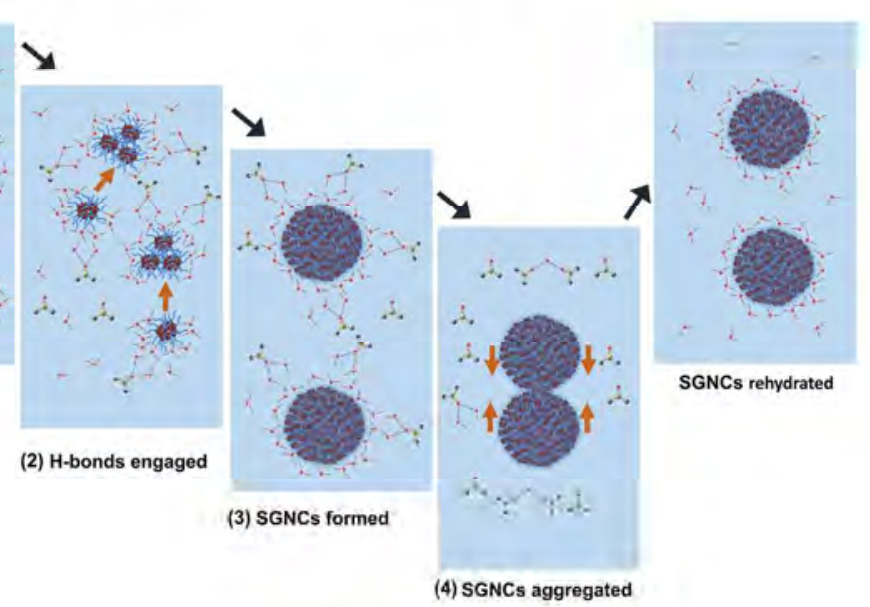

Figure 2. Dialysis-induced and solvent-dependent SGNCs formation. TEM images of the formed SGNCs when GNCs aqueous solution dialyzed against (a) DMSO and (b) DMF, respectively. (c-d) The core size distributions (histogram and Gaussian fitting) from TEM measurements of (a) and (b), respectively. Scale bars, $1 \mu \mathrm{m} \mathrm{(a);} 200 \mathrm{~nm}$ (b). (e) Schematic representation of the dialysis process of GNCs aqueous solution against DMSO solvent: (1) solvents diffusion, (2) H-bonds engaged, (3) SGNCs formed, (4) SGNCs aggregated. When the turbid solution in the dialysis bag was collected, precipitated, and resuspended in water, the SGNCs rehydrated and dispersed in water.

$150 \times 142 \mathrm{~mm}(300 \times 300 \mathrm{DPI})$ 

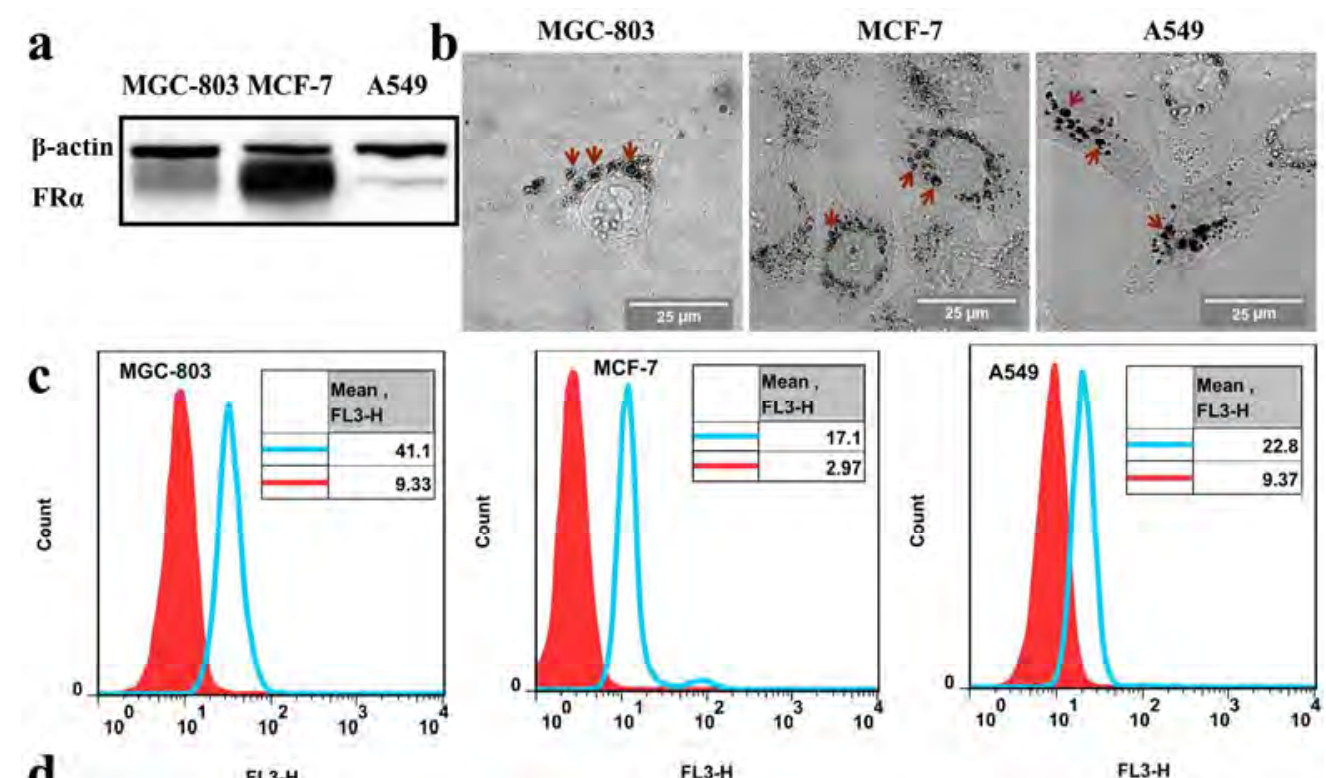

d
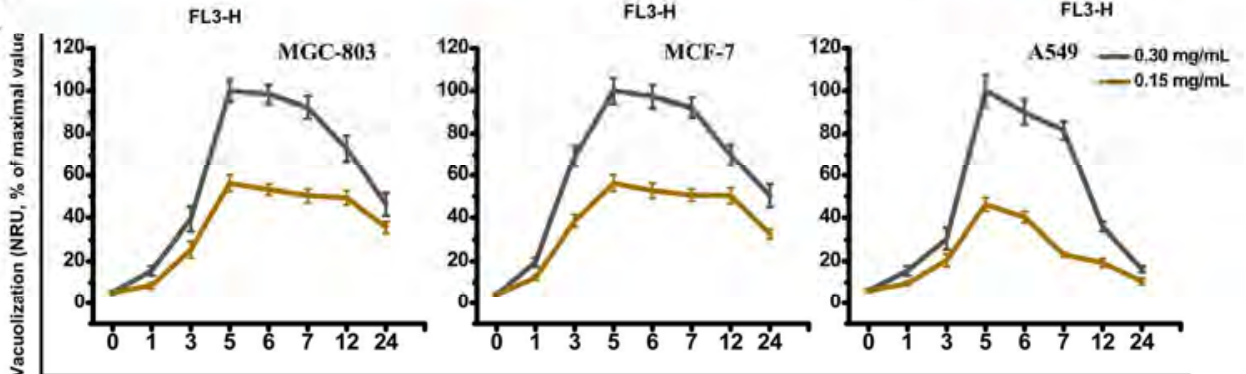

Time (h)

Figure 3. (a) Western blot analysis of FRa expression in MGC-803, MCF-7, and A549 cells. (b) Neutral red accumulated in MGC-803, MCF-7, and A549 cells after exposure to $0.15 \mathrm{mg} / \mathrm{mL}$ SGNCs-FA complexes for 2 $\mathrm{h}$, respectively. Arrowheads point at vacuoles completely stained with the neutral red. (c) Flow cytometry analysis of the cellular uptake of SGNCs-FA complexes. Red and cyan histograms represent fluorescence signals of the untreated cells, the cells treated with $0.15 \mathrm{mg} / \mathrm{mL}$ SGNCs-FA complexes for $2 \mathrm{~h}$, respectively.

(d) The dose-response and time-course of cytoplasmic vacuolization induced by SGNCs-FA complexes.

Neutral red accumulated in cells was quantified by $\mathrm{OD}_{550} \mathrm{~nm}$. The extent of cellular vacuolization was expressed as percent of the maximal observed uptake within the same experiment at the indicated time. All values shown were the average of quintuplicates \pm SD.

$183 \times 166 \mathrm{~mm}(300 \times 300 \mathrm{DPI})$ 

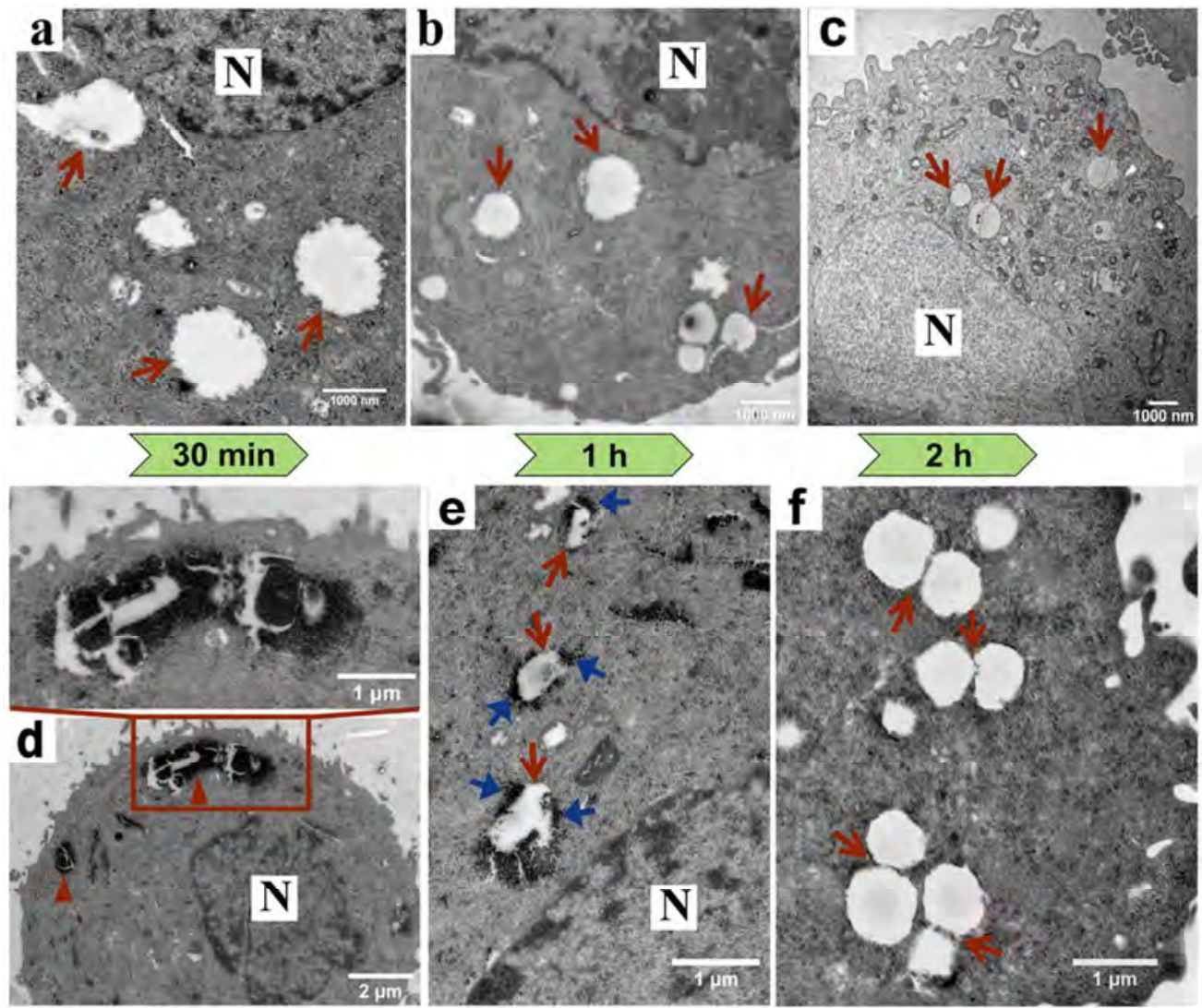

Figure 4. Ultrastructure observation of cytoplasmic vacuoles in (a) MGC-803, (b) MCF-7, and (c) A549 cell after co-incubation with $0.3 \mathrm{mg} / \mathrm{mL}$ SGNCs-FA complexes for $3 \mathrm{~h}$, respectively. The formation process of cytoplasmic vacuoles in MGC-803 cells at (d) $30 \mathrm{~min}$, (e) $1 \mathrm{~h}$, and (f) $2 \mathrm{~h}$ after co-incubation with 0.3 $\mathrm{mg} / \mathrm{mL}$ SGNCs-FA complexes. Red arrows in (a-c) point at the vacuoles; red triangles in (d) point at endocytic vesicle; red and blue arrows in (e) indicate the endocytic vesicles which are transforming into vacuoles and SGNCS-FA complexes which are escaping from vesicles into cytosol, respectively; red arrows in (f) indicate the fusion behaviors of cytoplasmic vacuoles. Abbreviation: N, nucleus. Scale bars, $1000 \mathrm{~nm}$ (ac); $2 \mu \mathrm{m}$ (d); $1 \mu \mathrm{m}$ (inset of $d, e, f$ ).

$88 \times 74 \mathrm{~mm}(300 \times 300 \mathrm{DPI})$ 

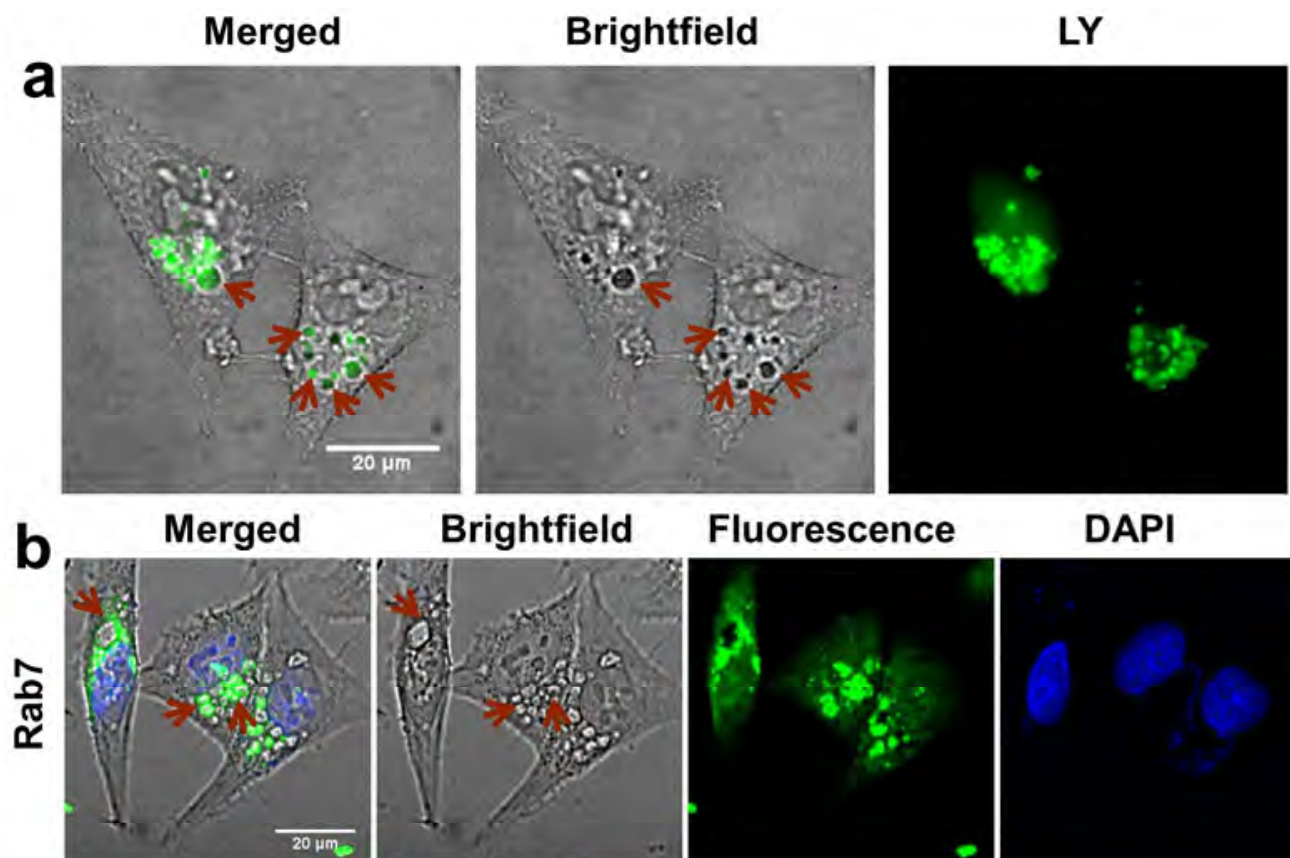

Brightfield
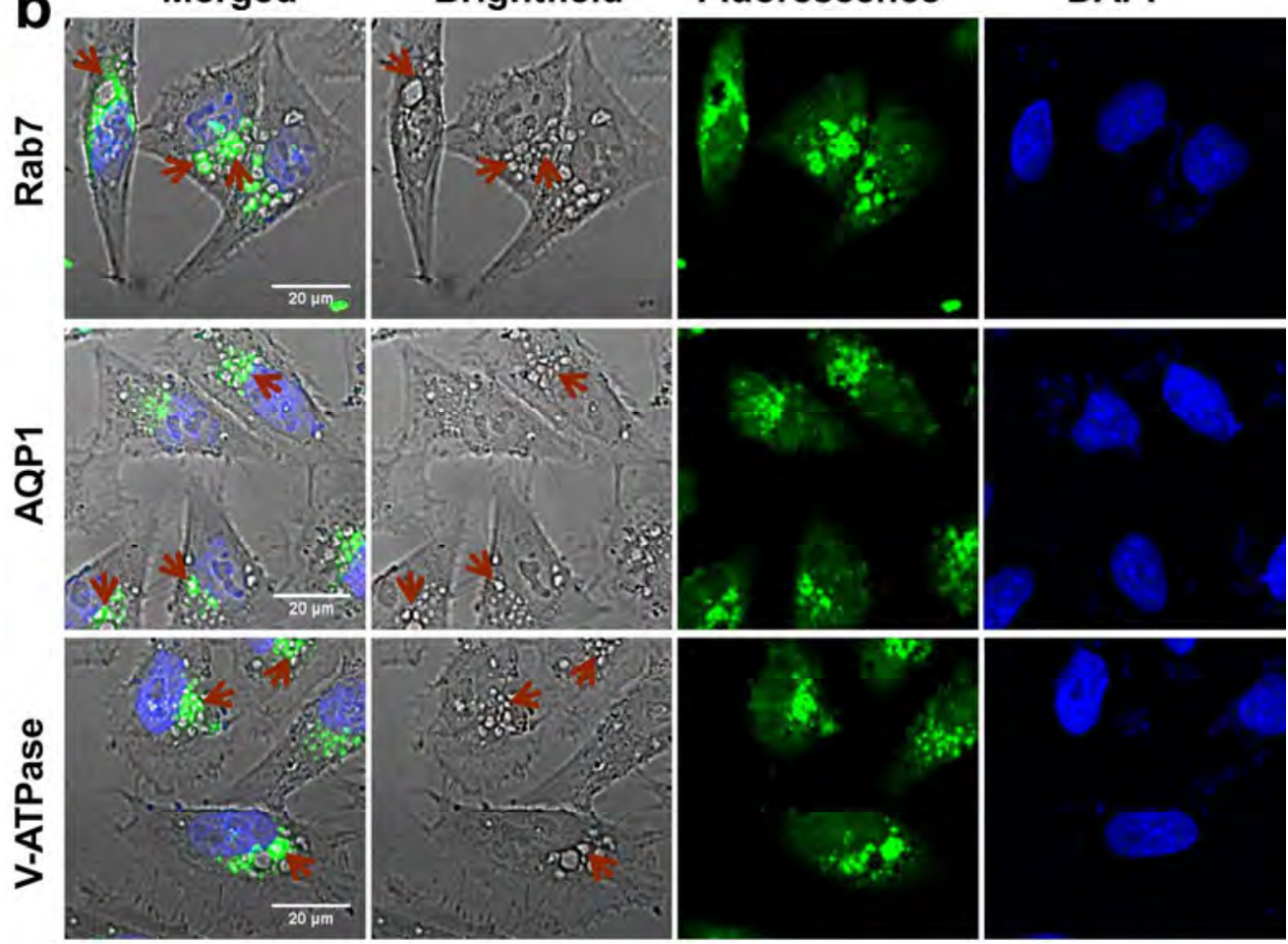

Figure 5. Fluorescent analysis of the cytoplasmic vacuoles. (a) Localization of LY in vacuolated MGC-803 cells induced by SGNCs-FA complexes. Arrowhead points at a subpopulation of LY-containing vacuoles. (b) Immunofluorescent staining of vacuolated MGC-803 cells for Rab7, AQP1, and V-ATPase. From right to left panel, representative DAPI blue fluorescence images of the nucleus, green fluorescence images of specific protein markers, brightfield microscopy images, and the merged images are presented. Arrowheads points at vacuoles. Scale bars, $20 \mu \mathrm{m}$. Abbreviations: LY, lucifer yellow; V-ATPase, vacuolar $\mathrm{H}^{+}$-ATPase; AQP1, Aquaporin 1; DAPI, 4'-6-diamidino-2-phenylindole.

$$
176 \times 201 \mathrm{~mm}(300 \times 300 \text { DPI })
$$



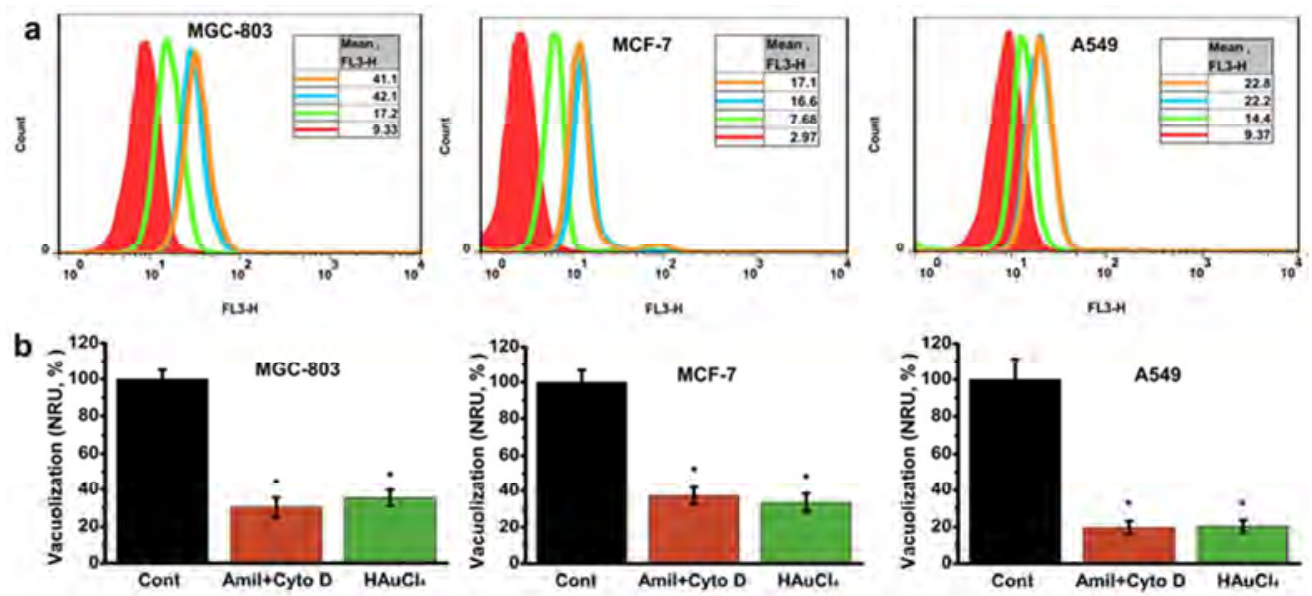

Figure 6. Pharmacological inhibition of macropinocytosis and AQP1. (a) Flow-cytometry-based analysis of the cellular uptake of SGNCs-FA complexes after pretreated with inhibitors. The red, green, cyan, and orange histograms represented fluorescence signals of the untreated cells, the cells with macropinocytosis inhibitors (amiloride $100 \mu \mathrm{g} / \mathrm{mL}+$ Cyto D $2 \mathrm{mM}, 2 \mathrm{~h}$ ) pretreating and subsequent SGNCs-FA complexes exposure, the cells with AQP1 inhibitor ( $\left.\mathrm{HAuCl}_{4} 200 \mu \mathrm{M}, 6 \mathrm{~min}\right)$ pretreating and subsequent SGNCs-FA complexes exposure, and the cells with SGNCs-FA complexes exposure. (b) The extent of SGNCs-FA-induced vacuolization in cells with or without inhibitors pretreating was determined by NRU assay. Cells without inhibitors pretreating but expose to SGNCs-FA complexes were taken as the control groups (set as $100 \%$ vacuolization efficiency). The pharmacological inhibitors pretreating and SGNCs-FA complexes exposure conditions in (b) were the same as used in (a). All values shown were the average of quintuplicates \pm SD. Statistical differences were determined by Student's $t$-test, * significant against the control group, $P<$ 0.001 .

$63 \times 29 \mathrm{~mm}(300 \times 300 \mathrm{DPI})$ 


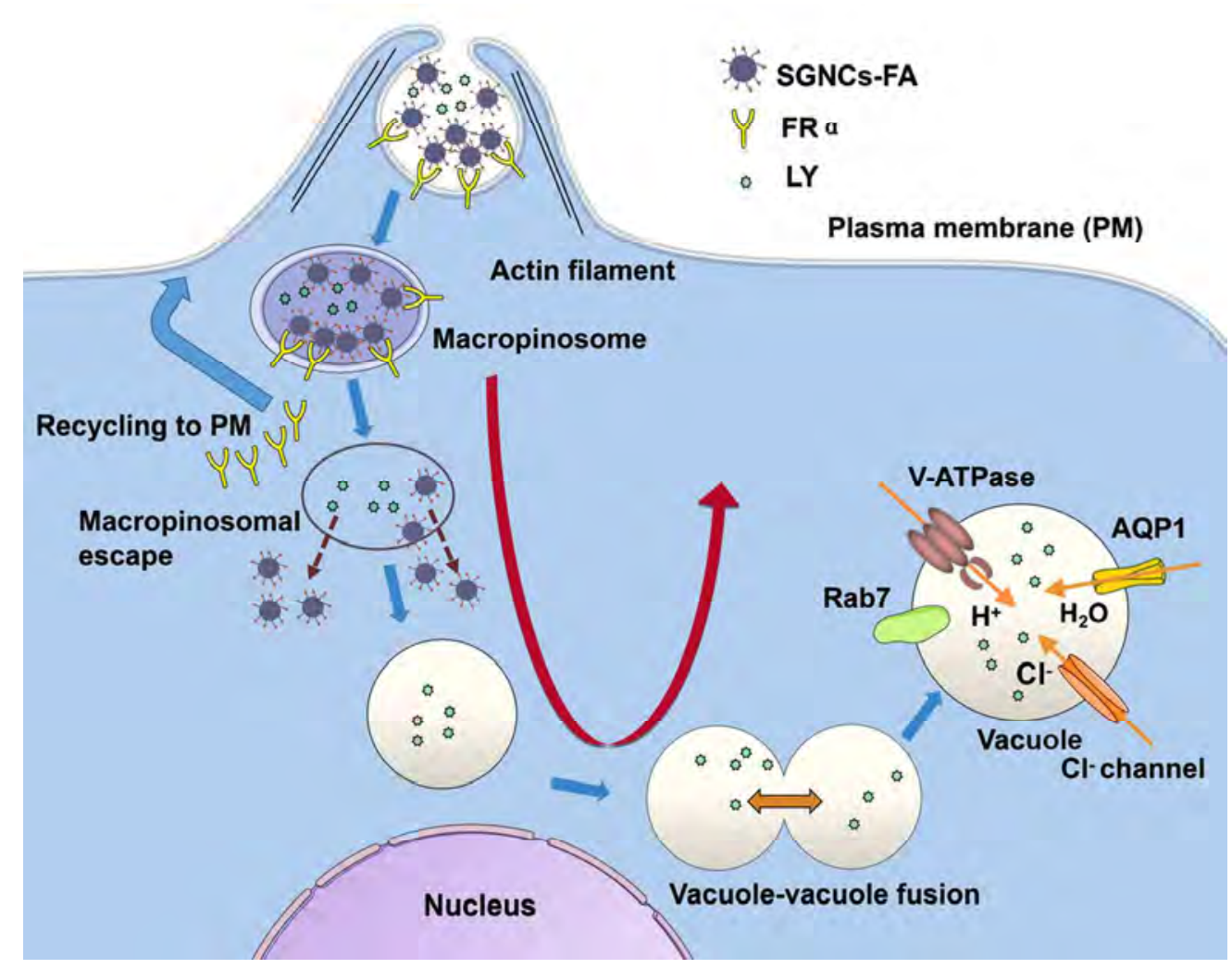

Figure 7. Schematic representation of how the SGNCS-FA complexes mimicking pathogenic invasion by the activation of macropinocytosis, the use of macropinosomal escape and inducing cytoplasmic vacuolization.

$100 \times 79 \mathrm{~mm}(300 \times 300 \mathrm{DPI})$ 


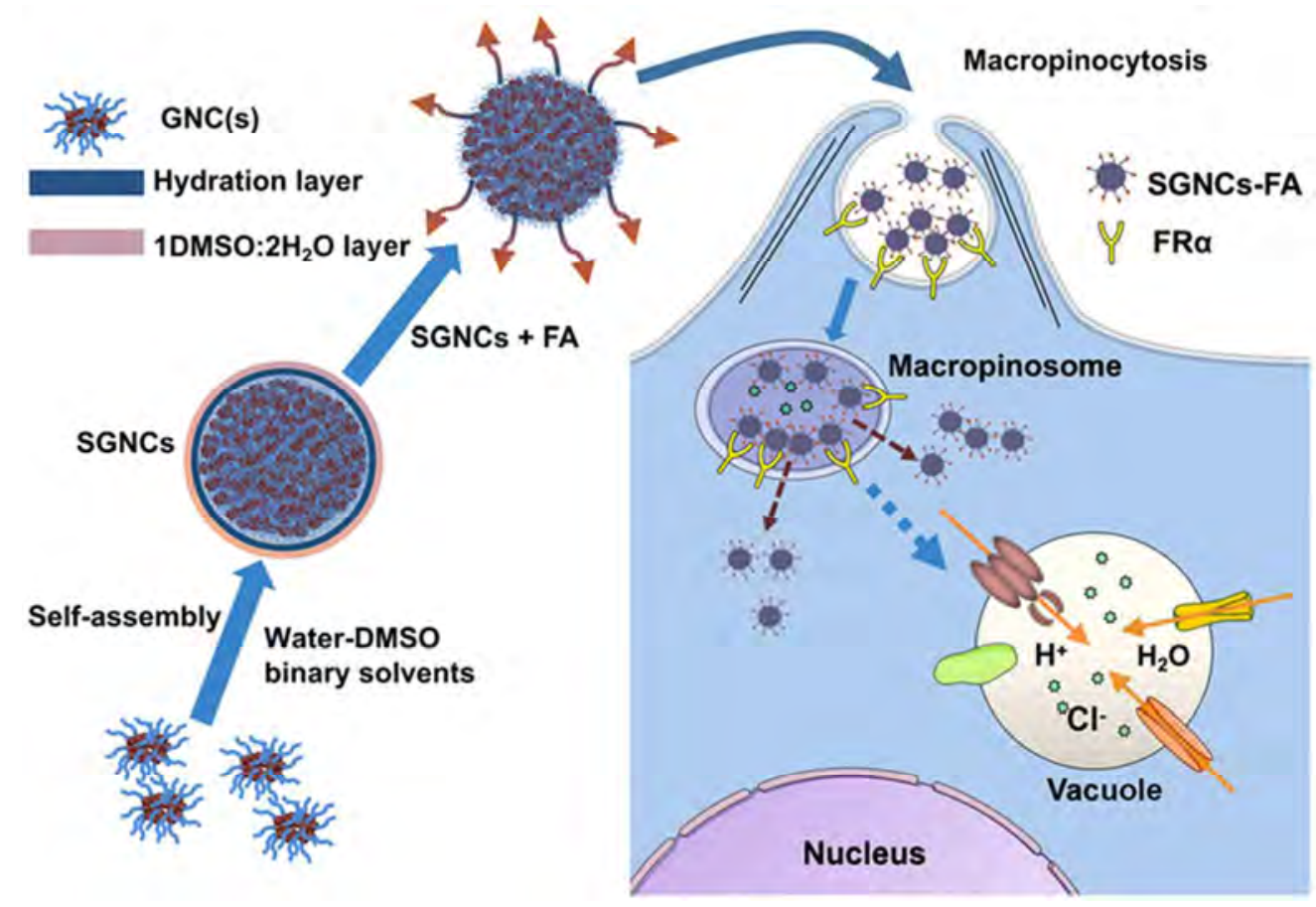

Table of contents graphic

$58 \times 40 \mathrm{~mm}(300 \times 300$ DPI $)$ 